\title{
WHOLE SEQUENCING OF THE MITOCHONDRIAL GENOME OF BREAST CANCER TISSUE IN MEXICAN-MESTIZO POSTMENOPAUSAL WOMEN WITH DIFFERENT BODY MASS INDEX
}

\author{
Nishi Adams-Reyes 1,2 , Ramón M. Coral-Vázquez ${ }^{3,4}$, Juan P. Méndez ${ }^{1,2}$, Alberto Tenorio ${ }^{5}$, \\ Juan C. Zenteno ${ }^{6,7}$, Vanessa Villegas-Ruiz ${ }^{7}$ and Patricia Canto ${ }^{1,2 *}$ \\ ${ }^{1}$ Obesity Research Unit, Faculty of Medicine, Universidad Nacional Autónoma de México; ${ }^{2}$ Obesity Clinic, Instituto \\ Nacional de Ciencias Médicas y Nutrición Salvador Zubirán; ${ }^{3}$ Postgraduate and Research Section, Escuela Superior \\ de Medicina, Instituto Politécnico Nacional; ${ }^{4}$ Sub directorate of Teaching and Research, Centro Médico Nacional \\ 20 de Noviembre, Instituto de Seguridad y Servicios Sociales de los Trabajadores del Estado; ${ }^{5}$ Instituto de \\ Enfermedades de la Mama, FUCAM; ${ }^{6}$ Biochemistry Department, Faculty of Medicine, Universidad Nacional \\ Autónoma de México; and ${ }^{7}$ Genetics Department, Research Unit, Instituto de Oftalmología \\ Conde de Valenciana, Mexico City, Mexico.
}

\begin{abstract}
Background: Mitochondrial and oxidative stress has been related to obesity and breast cancer being this cancer more frequent and more aggressive in postmenopausal women with obesity. Objective: The objective of this study was to investigate whether Mexican-Mestizo postmenopausal women with breast cancer and obesity present different somatic mutations in the mitochondrial DNA (mtDNA) when compared to women with normal body mass index (BMI). Subjects and Methods: We included six Mexican-Mestizo postmenopausal women bearing breast cancer and who underwent mastectomy or breast-conserving surgery. BMI was determined in each case. Patients' genomic DNA was isolated from blood leukocytes and tumor tissue samples. Whole mtDNA sequence was determined by MitoChip v2.0 mitochondrial resequencing array, and data were analyzed using the GeneChip Sequence Analysis Software. Tumor mtDNA sequence was compared with matched leukocyte mtDNA sequence. Results: Three women had a normal BMl and three presented obesity. Overall, we found 64 genetic variants: $53.1 \%$ were somatic mutations and $46.9 \%$ were polymorphisms; $44.1 \%$ were in the non-coding region and $55.9 \%$ were in genes that encode for mitochondrial proteins. Among the somatic mutations, $67.7 \%$ were in patients with normal BMl and $32.3 \%$ in patients with obesity. Conclusions: We did not find a higher frequency of mitochondrial somatic mutations in postmenopausal women with breast cancer and obesity compared to those with normal BMI. However, results could be due to the small number of women studied. (REV INVEST CLIN. 2019;71:237-45)
\end{abstract}

Key words: Breast cancer. Body mass index. Mexican-Mestizo postmenopausal women. Mitochondria genome. Somatic mutations.

\author{
Corresponding author: \\ *Patricia Canto \\ Unidad de Investigación en Obesidad \\ Facultad de Medicina \\ Universidad Nacional Autónoma \\ de México and Clínica de Obesidad \\ Instituto Nacional de Ciencias Médicas \\ y Nutrición Salvador Zubirán \\ Vasco de Quiroga, 15 \\ Col. Belisario Domínguez Sección XVI, Del. Tlalpan \\ C.P. 14080, Mexico City, Mexico \\ E-mail: ipcanto@yahoo.com.mx
}

Received for publication: 21-11-2018

Approved for publication: 30-01-2019

DOI: $10.24875 / R I C .19002909$ 


\section{INTRODUCTION}

Breast cancer is the most common malignancy and the leading cause of cancer-related death among women worldwide ${ }^{1}$. In Mexico, the mortality rate during 2012 was 14.76 deaths per 100,000 wom$e^{2}$. Genetic and other risk factors play a fundamental role in the onset of this disease. Diverse studies have suggested that obesity increases the risk of breast cancer in postmenopausal women and raises the incidence of metastatic breast tumors, resulting in higher rates of recurrence and increased mortality ${ }^{3}$. In Mexico, the latest National Health and Nutrition Survey demonstrated that the overall prevalence of obesity has risen from 21.5\% in 1993 to $33.3 \%$ in 2016 being more pronounced in women $(38.6 \%)^{4}$.

Mutations in mitochondrial DNA (mtDNA) have been found to play a role in the genesis of numerous cancers including breast cancer ${ }^{5-8}$. The mitochondrial genome is a 16.5-kilobase double-stranded circular DNA that contains no introns and includes 13 genes that encode proteins involved in aerobic respiration, 22 transfer RNAs, and 2 ribosomal RNAs. mtDNA is more vulnerable to mutations, due to high levels of reactive oxygen species (ROS) formed during oxidative phosphorylation, to a limited repair DNA system, and to the absence of protective histones ${ }^{9}$. Therefore, ROS are thought to be involved in the initiation, progression, and maintenance of tumorigenesis ${ }^{10}$.

Despite the current novel strategies for highthroughput screening of the mitochondrial genome such as the MitoChip used for investigating mtDNA mutations in various cancers ${ }^{11}$, studies aimed at detecting mutations in breast cancer often only analyze specific regions of mtDNA and not the entire mitochondrial genome ${ }^{12,13}$. Because mitochondrial defects and oxidative stress have been related to obesity ${ }^{14}$, and breast cancer is more frequent and more aggressive in postmenopausal women with obesity, we investigated whether MexicanMestizo postmenopausal women with breast cancer and obesity presented different somatic mutations in the mtDNA when compared to women with normal body mass index (BMI), using the second generation of MitoChip for sequencing all the mitochondrial genome.

\section{SUBJECTS AND METHODS}

\section{Study subjects}

The study was approved by the Human Research Committees of participating institutions. Informed written consent was obtained from all women before inclusion. Six postmenopausal women with diagnosis of breast cancer, who underwent mastectomy or breast-conserving surgery, were recruited from the Instituto de Enfermedades de la Mama (FUCAM), Mexico, during 2012 and 2013. All patients were of Mexican-Mestizo ethnic origin, from the central part of Mexico. Only women born in Mexico, who had a Spanish-derived last name and Mexican ancestors back to the third generation were considered Mexican-Mestizo.

A structured questionnaire was administered to all women in person, to define the potential risk factors for breast cancer; the following information was included: demographic data, medical and reproductive history, alcohol consumption, smoking habits, and physical activity (defined by regular physical activity at least 3 times a week for $30 \mathrm{~min}$ ). Exclusion criteria were as follows: women with a family history of breast cancer, previous radiotherapy and/or chemotherapy, locally advanced or metastatic carcinoma, or history of other past neoplasias. Body height and weight were measured at baseline, with the patient in a standing position, wearing a hospital gown, and without shoes. Women were categorized as having a healthy BMI if it was in the range of $20-24.9 \mathrm{~kg} / \mathrm{m}^{2}$ and being obese if it was $\geq 30.0 \mathrm{~kg} / \mathrm{m}^{2}$.

Histologic tumor grade was determined according to the modified Scarff-Bloom-Richardson score, as grades (G) G1, G2, and $G 3^{15}$. Node involvement was defined as positive ( $N \geq 1$; cancer cells found in one or more lymph nodes) or negative ( $\mathrm{N}=0$; absence of regional metastases). Furthermore, we evaluated lymphovascular invasion, classified as positive or negative according to the presence or absence of tumor cells in the lumen of lymphatic vessels or blood vessels. We followed all patients for 20-30 months.

\section{Immunohistochemistry (IHC)}

Immunohistochemical analysis of estrogen receptor (ER), progesterone receptor (PR), human epidermal 
growth factor receptor 2 (Her2), and Ki67 expression was carried out using $5-\mu \mathrm{m}$ consecutive tissue sections obtained from tissue samples. These sections were dewaxed in xylene and rehydrated in graded alcohols. After antigen unmasking and endogenous peroxidase removal, non-specific binding was blocked by incubating the slides for $1 \mathrm{~h}$ with $1.5 \%$ normal serum in PBS. Afterward, the sections were incubated with the primary antibodies. The following antibodies were used for IHC: for ER, monoclonal mouse antihuman ER, clone 1D5 (M7047) dilution 1:35; for PR, monoclonal mouse anti-human PR, clone PgR 636 (M3569) dilution 1:50; and for Ki67, monoclonal mouse anti-human Ki67 antigen, clone MIB-1 (M7240) dilution 1:100. All antibodies used were acquired from DAKO (DAKO, Glostrup, Denmark). Antibody-antigen reactions for ER and PR were determined by the avidin-biotin-peroxidase complex (ABC Staining System, Santa Cruz Biotechnology) and for Ki67 by the streptavidin-biotin-peroxidase complex (LSAB Kit, DAKO). All slides were counterstained with hematoxylin. Breast specimens previously classified as positive for the expression of the studied markers were used for control and protocol standardization. In negative controls, primary antibodies were omitted. Tumors in which at least $1 \%$ of cells expressed one or both receptors (ER and PR) were considered positive. Based on the 2015 St Gallen consensus standard $^{16}$, results of Ki67 expression were classified as low ( $\leq 15 \%$ of stained cells), medium (16-25\%), or high (> 26\%). The level of Her2 expression was determined by IHC with a HercepTest (DAKO) and scored as 0 (no staining), 1+ (faint, incomplete membranous pattern), 2+ (moderate complete membranous pattern), and $3+$ (strong membranous pattern). Samples with 0 and $1+$ scores were considered HER2negative and with a $3+$ score was considered Her2positive; in addition, in Her2 $2+$ cases, a fluorescence in situ hybridization or a chromogenic in situ hybridization was performed to confirm a positive or negative status.

\section{Molecular studies}

Genomic DNA of all patients was isolated from blood leukocytes using the salting out procedure described by Miller et al. ${ }^{17}$. In the six patients analyzed, fresh tumor tissue was obtained from the center of the tumor, being all tumor cells, and was processed after $4 \mathrm{~h}$ to isolate the DNA using the DNeasy Blood and
Tissue Kit (QIAGEN GmbH, Hilden, Germany) following conditions recommended by the manufacturer.

\section{MitoChip v2.0 sequencing}

mtDNA sequence of both leukocyte and tumor tissue samples was determined by MitoChip v 2.0 mitochondrial resequencing array (Affymetrix; Santa Clara, CA, USA), following the standard Affymetrix protocol ${ }^{18}$. The Affymetrix MitoChip v.2.0 is formed by overlapping 25-mers on high-density oligonucleotide arrays with $8 \times 8$-m features that represent the complete sequences of both strands of the entire 16,568-bp human mitochondrial genome. The Cambridge Reference Sequence (rCRS, NC_012920) was tiled, as well as sequences representing 500 of the most common haplotypes recorded in the MitoMap public database http://www.mitomap.org/, which includes single-nucleotide changes, insertions, and deletions. To investigate any given site from the human mitochondrial reference sequence, four features are tiled on the MitoChip. The four features differ only by the central or 13th base, which consists of each of the four possible nucleotides.

Microarray data from the MitoChip v2.0 were analyzed using the GeneChip Sequence Analysis Software (GSEQ) v4.0, with a statistical framework based on the algorithm of ABACUS ${ }^{19}$, to assign to each position, the basis that meets the quality criteria in the mitochondrial genome. Mitochondrial tumor DNA sequence was compared to matched leukocyte mtDNA sequence, to identify true mutations rather than polymorphisms.

The raw sequencing data of the microarray were deposited in gene expression omnibus (GEO) (https://www. ncbi.nlm.nih.gov/geo/) database, code: GSM3582026.

\section{RESULTS}

Three women had a normal BMI and three presented obesity; all patients were postmenopausal. One of the women with a normal BMI was the oldest in the group (82 years) and presented a locally advanced breast cancer (Stage IIB). In the group of women with obesity, one woman had a higher proliferation index (Ki67) of $75 \%$. Regarding the immunohistochemical subtypes, hormonal receptor (+)/HER2 (-) was found 
Table 1. Clinicopathologic characteristics of Mexican-Mestizo women with breast cancer and normal BMl or obesity

\begin{tabular}{|c|c|c|c|c|c|c|c|c|c|}
\hline I.D. & Age (years) & BMI & Grade & TNM & Stage & ER & PR & Her $2 \mathrm{Neu}$ & Ki67 (\%) \\
\hline 1 & 48 & 23.1 & II & T2NOMO & IIA & + & + & - & 5 \\
\hline 2 & 59 & 20.7 & II & T2NOMO & $\| A$ & + & + & - & 8 \\
\hline 3 & 82 & 20.1 & II & T3NOMO & IIB & + & + & - & 15 \\
\hline 4 & 51 & 31.5 & II & T1N1M0 & $\| A$ & + & + & - & 75 \\
\hline 5 & 59 & 32.8 & II & T2NOMO & $\| A$ & + & + & - & 10 \\
\hline 6 & 68 & 32.3 & II & T2NOMO & IIA & + & + & - & 15 \\
\hline
\end{tabular}

Patients 1-3 had normal BMI; patients 4-6 had obesity.

BMI: body mass index, ER: estrogen receptor, PR: progesterone receptor.

Table 2. Somatic mutations in the non-coding region of the mtDNA in Mexican-Mestizo women with breast cancer and normal BMI or obesity

\begin{tabular}{|c|c|c|c|c|c|c|}
\hline I.D. & Locus & Gene & $\begin{array}{l}\text { Reference } \\
\text { sequence }\end{array}$ & $\begin{array}{c}\text { Base in } \\
\text { peripheral blood }\end{array}$ & $\begin{array}{l}\text { Base } \\
\text { in tumor }\end{array}$ & Reported \\
\hline \multicolumn{7}{|c|}{ Women with normal BMI } \\
\hline 1 & 96 & D-Loop & $\mathrm{T}$ & $\mathrm{T}$ & G & NO \\
\hline 2 & 138 & D-Loop & $\mathrm{T}$ & $\mathrm{T}$ & C & NO \\
\hline 1 & 679 & $12 S$ rRNA & C & C & A & NO \\
\hline 1 & 1440 & $12 S$ rRNA & G & G & $\mathrm{T}$ & NO \\
\hline 1 & 2890 & 16S rRNA & $\mathrm{T}$ & $\mathrm{T}$ & C & NO \\
\hline $3^{*}$ & 4361 & tRNA Gln & A & A & $\mathrm{A} / \mathrm{C}$ & NO \\
\hline 3 & 16113 & D-Loop & $\mathrm{T}$ & $\mathrm{T}$ & $\mathrm{C}$ & NO \\
\hline 2 & 16215 & D-Loop & A & A & C & NO \\
\hline 3 & 16521 & D-Loop & A & A & C & NO \\
\hline \multicolumn{7}{|c|}{ Women with obesity } \\
\hline 5 & 65 & D-Loop & $\mathrm{T}$ & $\mathrm{T}$ & C & NO \\
\hline 5,6 & 147 & D-Loop & C & C & $\mathrm{T}$ & NO \\
\hline $4,5,6^{* *}$ & 664 & $12 \mathrm{~S}$ rRNA & G & G & A & YES \\
\hline 4 & 828 & $12 \mathrm{~S}$ rRNA & C & C & A & NO \\
\hline $4,5,6$ & 1737 & 16S rRNA & A & A & G & NO \\
\hline $6 *$ & 2351 & $16 \mathrm{~S}$ rRNA & $\mathrm{T}$ & $\mathrm{T}$ & $\mathrm{G} / \mathrm{T}$ & NO \\
\hline
\end{tabular}

*Patients with heteroplasmic variant. ${ }^{* *}$ Reported by Liu et al. ${ }^{27}$, in human ovarian carcinoma.

Revised Cambridge Reference Sequence (rCRS) of the Human Mitochondrial DNA.

www.mitomap.org//bin/view.pl/MITOMAP/HumanMitoCode; www.mitomap.org/foswiki/bin/view/MITOMAP/HumanMitoSeq; www.mitomap.org/ foswiki/bin/view/MITOMAP/MutationsSomatic; www.mtdb.igp.uu.se

mtDNA: mitochondrial DNA, BMI: body mass index.

in all cases. General characteristics are presented in table 1. After sequencing the complete mitochondrial genome and comparing it with that reported in the Revised Cambridge Reference Sequence (rCRS) of the Human mtDNA (www.mitomap.org/foswiki/bin/ view/MITOMAP/MutationsSomatic) and mtDB - Human Mitochondrial Genome Database (www.mtdb. igp.uu.se/), we found 64 genetic variants, 34 (53.1\%) were in the tumor tissue and were not present in the DNA of blood leukocytes (somatic mutations), and 30 (46.9\%) were polymorphisms (Tables 2-4). We observed only two heteroplasmic mutations, both in the non-coding region (Table 2 ). Of all somatic variants, $15(44.1 \%)$ were in the non-coding region, 9 (60.0\%) 
Table 3. Somatic mutations in the coding region of the mtDNA in Mexican-Mestizo women with breast cancer and normal BMI or obesity

\begin{tabular}{|c|c|c|c|c|c|c|c|c|}
\hline I.D. & Locus & Gene & $\begin{array}{l}\text { Reference } \\
\text { sequence }\end{array}$ & $\begin{array}{c}\text { Base in } \\
\text { peripheral } \\
\text { blood }\end{array}$ & $\begin{array}{l}\text { Base } \\
\text { in tumor }\end{array}$ & $\begin{array}{l}\text { Codon } \\
\text { change }\end{array}$ & $\begin{array}{l}\text { Amino acid } \\
\text { change }\end{array}$ & Reported \\
\hline \multicolumn{9}{|c|}{ Women with normal BMI } \\
\hline 1 & 3399 & ND1 & $A$ & $A$ & G & ATA $>$ ATG & M31M & NO \\
\hline 2 & 4978 & ND2 & $\mathrm{T}$ & $\mathrm{T}$ & $\mathrm{C}$ & $\mathrm{TTA}>\mathrm{TCA}$ & L170S & NO \\
\hline 3 & 4979 & ND2 & $\mathrm{T}$ & $\mathrm{T}$ & C & TTA $>$ TTC & L170F & NO \\
\hline 2 & 5376 & ND2 & A & A & G & $A C A>G C A$ & T303A & NO \\
\hline 2,3 & 6475 & $\mathrm{CO} 1$ & $\mathrm{C}$ & C & $\mathrm{T}$ & ACA $>$ ATA & T191M & NO \\
\hline 3 & 6897 & $\mathrm{CO} 1$ & $A$ & $A$ & G & ATG $>$ GTG & M332V & NO \\
\hline 3 & 7243 & $\mathrm{CO} 1$ & A & A & G & $\mathrm{TAC}>\mathrm{TGC}$ & T447C & $\mathrm{NO}$ \\
\hline $1,2,3$ & 8796 & ATP6 & $\mathrm{C}$ & $\mathrm{C}$ & $\mathrm{T}$ & $\mathrm{CAC}>\mathrm{CAT}$ & $\mathrm{H} 9 \mathrm{OH}$ & NO \\
\hline 2 & 10174 & ND3 & G & G & $A$ & TGC $>$ TAC & C39Y & NO \\
\hline 2 & 11179 & ND4 & C & $C$ & $\mathrm{~T}$ & $\mathrm{CCA}>\mathrm{CCT}$ & P140P & NO \\
\hline 1 & 12942 & ND5 & $\mathrm{C}$ & C & $A$ & $\mathrm{GCC}>\mathrm{GCA}$ & A202A & NO \\
\hline 3 & 12956 & ND5 & $A$ & $A$ & C & $\mathrm{AAT}>\mathrm{ACT}$ & N207T & NO \\
\hline 2 & 13592 & ND5 & C & C & $A$ & $\mathrm{ACA}>\mathrm{AAA}$ & T419K & NO \\
\hline 1 & 13932 & ND5 & C & C & $\mathrm{T}$ & ATC $>$ ATT & $1532 \mid$ & NO \\
\hline \multicolumn{9}{|c|}{ Women with obesity } \\
\hline 4 & 4822 & ND2 & $\mathrm{T}$ & $\mathrm{T}$ & G & GTT>GGT & V118G & NO \\
\hline 6 & 4825 & ND2 & $C$ & $C$ & $A$ & $A C C>A A C$ & $\mathrm{~T} 119 \mathrm{~N}$ & NO \\
\hline 6 & 5040 & ND2 & A & A & $C$ & ATA $>$ CTA & M191L & NO \\
\hline 6 & 5067 & ND2 & $A$ & A & G & ATA $>$ GTA & M200V & NO \\
\hline 6 & 6895 & $\mathrm{CO} 1$ & $A$ & $A$ & G & AAT>AGT & N331S & NO \\
\hline
\end{tabular}

Revised Cambridge Reference Sequence (rCRS) of the Human Mitochondrial DNA.

www.mitomap.org//bin/view.pl/MITOMAP/HumanMitoCode; www.mitomap.org/foswiki/bin/view/MITOMAP/HumanMitoSeq; www.mitomap.org/ foswiki/bin/view/MITOMAP/MutationsSomatic; www.mtdb.igp.uu.se mtDNA: mitochondrial DNA, BMI: body mass index.

in patients with normal $\mathrm{BMI}$, and $6(40.0 \%)$ in patients with obesity (Table 2 ). On the other hand, we found 19 (55.9\%) mutations in the tumor tissue that was not present in blood leukocytes DNA, in genes encoding mitochondrial proteins. Patients with normal BMI presented 14 (73.7\%) mutations, 5 were synonymous, and the rest changed the amino acids (Table 3 ). Regarding the patients with obesity, we found only $5(26.3 \%)$ mutations, being all non-synonymous changes (Table 3 ).

Polymorphisms were more frequent in patients with obesity, finding 21 variants in the coding region ( $66.7 \%$ of them were polymorphisms synonymous) and 5 in the D-loop region (Table 4). The four polymorphisms detected in patients with normal BMI were two in D-loop region and the other two in genes that encode mitochondrial proteins (Table 4). We also found 25 genetic variations that were present in both, tumor tissue and DNA of blood leukocytes, $60 \%$ of which had not been reported previously. $40 \%$ of these genetic variants were polymorphisms, and $80 \%$ were found in the non-coding region (data not shown).

\section{DISCUSSION}

Obesity is a major risk factor for breast cancer, and it has been suggested that adiposity increases the risk of recurrence and mortality in affected women, worsening quality of life ${ }^{3}$. Mitochondrial dysfunction has been implicated in the pathophysiology of both, 
Table 4. Polymorphisms in the non-coding and coding region of the mtDNA in Mexican-Mestizo women with breast cancer and normal BMI or obesity

\begin{tabular}{|c|c|c|c|c|c|c|c|}
\hline I.D. & Locus & Gene & $\begin{array}{l}\text { Reference } \\
\text { sequence }\end{array}$ & $\begin{array}{l}\text { Base in } \\
\text { peripheral } \\
\text { blood }\end{array}$ & $\begin{array}{c}\text { Base } \\
\text { in tumor }\end{array}$ & Codon change & $\begin{array}{l}\text { Amino acid } \\
\text { change }\end{array}$ \\
\hline \multicolumn{8}{|c|}{ Women with normal BMI } \\
\hline $1,2,3$ & 4824 & ND2 & $A$ & $A$ & G & $\mathrm{ACC}>\mathrm{GCC}$ & T119A \\
\hline 3 & 14755 & CytB & $A$ & A & C & $\mathrm{CCA}>\mathrm{CCC}$ & P3P \\
\hline 3 & 16219 & D-Loop & $A$ & A & G & - & - \\
\hline 3 & 16292 & D-Loop & C & C & $\mathrm{T}$ & - & - \\
\hline \multicolumn{8}{|c|}{ Women with obesity } \\
\hline 6 & 154 & D-Loop & $\mathrm{T}$ & $\mathrm{T}$ & C & - & - \\
\hline 5,6 & 3547 & ND1 & $A$ & A & G & ATC $>$ GTC & $181 \mathrm{~V}$ \\
\hline 5,6 & 4248 & ND1 & $\mathrm{T}$ & $\mathrm{T}$ & C & ATT $>$ ATC & $|314|$ \\
\hline 5,6 & 4820 & ND2 & G & G & A & $G A G>G A A$ & E117E \\
\hline $4,5,6$ & 4977 & ND2 & $\mathrm{T}$ & $\mathrm{T}$ & C & $\mathrm{TTA}>\mathrm{CTA}$ & L170L \\
\hline 5 & 6152 & $\mathrm{CO} 1$ & $\mathrm{~T}$ & $\mathrm{~T}$ & C & GTT>GTC & V83V \\
\hline 4 & 6216 & $\mathrm{CO} 1$ & $T$ & $\mathrm{~T}$ & C & $\mathrm{TTA}>\mathrm{CTA}$ & L105L \\
\hline 5,6 & 6473 & $\mathrm{CO} 1$ & $C$ & C & T & ATC $>$ ATT & $|190|$ \\
\hline 6 & 7241 & $\mathrm{CO} 1$ & A & A & G & $\mathrm{GCA}>\mathrm{GCG}$ & A 446A \\
\hline $4,5,6$ & 8027 & $\mathrm{CO} 2$ & G & G & A & $\mathrm{GCC}>\mathrm{ACC}$ & $\mathrm{A} 148 \mathrm{~T}$ \\
\hline $4,5,6$ & 8794 & ATP6 & $C$ & C & $\mathrm{T}$ & $C A C>T A C$ & H9OY \\
\hline $4,5,6$ & 9950 & $\mathrm{CO} 3$ & $T$ & $\mathrm{~T}$ & C & $\mathrm{GTT}>\mathrm{GTC}$ & V248V \\
\hline 5 & 10172 & ND3 & G & G & A & GAG $>\mathrm{GAA}$ & E38E \\
\hline 6 & 11016 & ND4 & G & G & A & AGT $>$ AAT & S86N \\
\hline $4,5,6$ & 11177 & ND4 & $C$ & C & $\mathrm{T}$ & $C C A>T C A$ & P140S \\
\hline $4,5,6$ & 12007 & ND4 & G & G & A & TGG $>$ TGA & W416W \\
\hline $4,5,6$ & 12705 & ND5 & $C$ & $C$ & $\mathrm{~T}$ & ATC $>$ ATT & $|123|$ \\
\hline 6 & 12954 & ND5 & $T$ & $\mathrm{~T}$ & C & $\mathrm{GCT}>\mathrm{GCC}$ & A206A \\
\hline $4,5,6$ & 13590 & ND5 & G & G & A & CTG $>$ CTA & L418L \\
\hline 6 & 14757 & CytB & $T$ & $\mathrm{~T}$ & C & ATA $>A C A$ & M4T \\
\hline 5 & 15313 & CytB & $\mathrm{T}$ & $\mathrm{T}$ & C & ATT $>$ ATC & |189| \\
\hline 4 & 15824 & CytB & A & A & G & $A C A>G C A$ & T360A \\
\hline 5 & 16086 & D-Loop & $T$ & $\mathrm{~T}$ & C & - & - \\
\hline $4,5,6$ & 16217 & D-Loop & $T$ & $T$ & C & - & - \\
\hline $4,5,6$ & 16223 & D-Loop & $C$ & $C$ & $\mathrm{~T}$ & - & - \\
\hline 5,6 & 16519 & D-Loop & $\mathrm{T}$ & $\mathrm{T}$ & $C$ & - & - \\
\hline
\end{tabular}

Revised - www.mtdb.igp.uu.se

mtDNA: mitochondrial DNA, BMI: body mass index.

obesity and breast cancer ${ }^{14,20}$. Several somatic mutations have been reported in mtDNA in women with breast cancer. However, these studies have been conducted in women of Caucasian and Asian ethnicity ${ }^{6,7,21,22}$; for that reason, we considered it important to study somatic mitochondrial mutations in patients with breast cancer and different BMI who belonged to a distinct ethnic group. The latter is relevant since different lineages of mtDNA are associated with diverse global population groups ${ }^{23}$. This raises the 
possibility that mtDNA variations could contribute to differences observed in disease prevalence reported among different ethnic groups. Likewise, it is important to consider that Mexican-Mestizo population is constituted by a mixture of Europeans and Africans with native Indian individuals ${ }^{24}$. The proportion of genes in this ethnic group has been reported as $56 \%$ Amerindian, 40\% Caucasian, and 4\% African genes ${ }^{25}$.

There are few studies, in breast cancer patients, where the whole mtDNA is sequenced in search of somatic mutations. Furthermore, these studies do not consider the presence of obesity as a risk factor. In several studies, it has been reported that the Dloop region of mtDNA is the most frequent site of mutations in breast cancer ${ }^{5-7,21,22}$. Parrella et al. ${ }^{5}$ examined by direct sequence analysis, the mtDNA of 16 women with primary breast cancer. Despite having analyzed only $84 \%$ of the mtDNA, they identified 12 somatic mutations and several polymorphisms; the highest frequencies of mutations were detected in the D-loop region. Tan et al. ${ }^{6}$, studying the complete sequence of the mtDNA of breast cancer tissue, found that $74 \%$ of the analyzed tumors had somatic mutations, and most of these mutations were also found in the hypervariable D-loop region. These authors mentioned that some of these somatic mutations had been described in other cancers (i.e., ovarian carcinomas, esophageal cancer, colorectal, and gastric tumors). Likewise, Zhu et al. ${ }^{7}$ sequenced the entire mtDNA of 15 breast cancer tissue samples detecting several polymorphisms and 45 somatic mutations in $93 \%$ of the tumors. Most of these mutations were homoplasmic and the majority of them, as well as the polymorphisms, were also located within the D-loop region. However, unlike the studies cited above, we found more somatic mutations in those genes that encode proteins involved in aerobic respiration, then somatic mutations located in the non-coding region. Moreover, we did not find the mononucleotide repeat, between nucleotides 303 and 315 (D310), which is a conserved sequence of mtDNA and has been considered a hotspot region ${ }^{5,7}$.

Differences between our results and those previously reported might be due to the screening approaches used in the studies mentioned above. In most of the previous studies, only a portion of the mitochondrial genome was screened. Likewise, some of the screening techniques used, such as temperature gradient gel electrophoresis, may miss some mutations. On the other hand, we used an Affymetrix MitoChip, and as has been proposed by Xie et al. ${ }^{26}$, this tool has a high sensitivity and accuracy needed for reliable, whole mitochondrial genome sequencing. Moreover, we observed that women with breast cancer and a normal BMI had more somatic mutations in genes that encode mitochondrial proteins than women with obesity. These mutations were present in $\mathrm{NADH}$ dehydrogenase (ND) subunit 1 (ND1), subunit 2 (ND2), subunit 3 (ND3), subunit 4 (ND4), subunit 5 (ND5), ATP synthase 6 (ATP6), and cytochrome oxidase subunit I genes; most of these changes were non-synonymous. Interestingly, patient 3 showed 9 somatic mutations, where 8 of them changed amino acids. Probably in this patient, advanced age ( 82 years) and the presence of a more advanced cancer (IIB stage) contributed to the existence of a higher number of mutations.

In relation to those somatic mutations observed in the non-coding region in women with obesity, only the mutation at position 664 of the $12 \mathrm{~S}$ ribosomal RNA (present in all three patients with obesity) had been reported previously in human ovarian carcinoma ${ }^{27}$. In addition, of the five non-synonymous somatic mutations present in genes that encode mitochondrial proteins, found in our women with obesity, four of them were present in patient 6 and almost all were in ND2. It has been hypothesized that ND2 is involved in proton translocation across the inner mitochondrial membrane, contributing to $\mathrm{pH}$ cell regulation. It has been demonstrated that the hydrophobic subunit of complex I is highly conserved throughout evolution, from bacteria to mice and to humans, indicating a central physiological role ${ }^{28}$.

Noteworthy, the patients with breast cancer and obesity presented a significant number of somatic polymorphisms. Most of these polymorphisms were in genes that encode mitochondrial proteins; some of them have been described in thyroid, prostate, pancreatic, and breast cancer (www.mitomap.org/foswiki/bin/view/MITOMAP/MutationsSomatic). This indicates that mtDNA is highly susceptible to mutation, probably by oxidative stress ${ }^{29}$. It has been proposed that these mtDNA variants, together with somatic mtDNA mutations, could create an environment with a slight increase in levels of ROS inside the 
mitochondria ${ }^{30}$; from the consequent signal transduction, cell proliferation may be augmented.

The main limitation of this study was that we only examined six patients with breast cancer; despite this limitation, the strengths of the study are that we analyzed the whole sequence of the mtDNA, and we compared women with normal BMl versus women with obesity.

To the best of our knowledge, this is the first report where the complete sequence of mtDNA in MexicanMestizo postmenopausal women with breast cancer and different BMl is performed, using human microarray data from the MitoChip. However, we did not find a higher frequency of mitochondrial somatic mutations in postmenopausal women with breast cancer and obesity. The latter may be due to the small number of women with obesity or normal BMI studied, so we could consider this a pilot study that needs to be confirmed in future studies with larger sample sizes.

Furthermore, due to the limited number of women with obesity and breast cancer studied, we could not demonstrate whether mitochondrial mutations in obesity are a risk factor for developing this type of cancer. We found that women with obesity had a greater number of polymorphisms which could be relevant for the presence of this cancer since the synonymous or synonymous codons usage could affect other aspects of protein biogenesis or regulate the expression level, which could be linked to human diseases $^{31}$. Besides, our results diverge from those reported in Caucasian and Asian populations, possibly due to ethnic differences. We believe that further studies are needed, where a larger number of patients with breast cancer are included. Furthermore, extensive biochemical and molecular studies will be necessary to determine the effects on energy metabolism in malignant cells.

\section{ACKNOWLEDGMENTS}

Nishi Adams Reyes was supported by a fellowship award from National Council for Science and Technology (Consejo Nacional de Ciencia y Tecnología, CONACYT), Mexico. We thank Drs. Carlos Domínguez Reyes and Felipe Villegas Carlos, from Instituto de Enfermedades de la Mama, FUCAM, for their support in the clinical phase of the study.

\section{REFERENCES}

1. Ferlay J, Soerjomataram I, Dikshit R, Eser S, Mathers C, Rebelo $M$, et al. Cancer incidence and mortality worldwide: sources, methods and major patterns in GLOBOCAN 2012. Int J Cancer. 2015;136:E359-86.

2. Available from: http://www.infocancer.org.mx/mortalidad-con894i0.html. [Accessed September 2, 2017].

3. Chan DS, Vieira AR, Aune D, Bandera EV, Greenwood DC, McTiernan $A$, et al. Body mass index and survival in women with breast cancer-systematic literature review and meta-analysis of 82 follow-up studies. Ann Oncol. 2014;25:1901-14.

4. Instituto Nacional de Salud Pública. Encuesta Nacional de Salud y Nutrición de Medio Camino (ENSANUT MC). México: Instituto Nacional de Salud Pública, Secretaría de Salud; 2016.

5. Parrella $P$, Xiao $Y$, Fliss M, Sanchez-Cespedes M, Mazzarelli P, Rinaldi $M$, et al. Detection of mitochondrial DNA mutations in primary breast cancer and fine-needle aspirates. Cancer Res. 2001;61:7623-6.

6. Tan DJ, Bai RK, Wong LJ. Comprehensive scanning of somatic mitochondrial DNA mutations in breast cancer. Cancer Res. 2002;62:972-6.

7. Zhu W, Qin W, Bradley P, Wessel A, Puckett CL, Sauter ER et al. Mitochondrial DNA mutations in breast cancer tissue and in matched nipple aspirate fluid. Carcinogenesis. 2005;26:145-52.

8. Bai RK, Leal SM, Covarrubias D, Liu A, Wong LJ. Mitochondrial genetic background modifies breast cancer risk. Cancer Res. 2007;67:4687-94

9. Jackson AL, Chen R, Loeb LA. Induction of microsatellite instability by oxidative DNA damage. Proc Natl Acad Sci U S A. 1998; 95:12468-73.

10. Benhar M, Engelberg D, Levitzki A. ROS, stress-activated kinases and stress signaling in cancer. EMBO Rep. 2002;3:420-5.

11. Maitra A, Cohen Y, Gillespie SE, Mambo E, Fukushima N, O. Hoque $M$, et al. The human mito chip: a high-throughput sequencing microarray for mitochondrial mutation detection. Genome Res. 2004;14:812-9.

12. Grzybowska-Szatkowska L, Slaska B, Rzymowska J, Brzozowska A, Floriańczyk B. Novel mitochondrial mutations in the ATP6 and ATP8 genes in patients with breast cancer. Mol Med Rep. 2014; 10:1772-8

13. Thapa S, Lalrohlui F, Ghatak S, Zohmingthanga J, Lallawmzuali $D$, Pautu JL, et al. Mitochondrial complex I and $V$ gene polymorphisms associated with breast cancer in Mizo-Mongoloid population. Breast Cancer. 2016;23:607-16

14. Lindinger PW, Christe M, Eberle AN, Kern B, Peterli R, Peters T, et al. Important mitochondrial proteins in human omental adipose tissue show reduced expression in obesity. J Proteomics. 2015;124:79-87

15. Le Doussal V, Tubiana-Hulin M, Friedman S, Hacene K, Spyratos F, Brunet M. Prognostic value of histologic grade nuclear components of scarff-bloom-richardson (SBR). An improved score modification based on a multivariate analysis of 1262 invasive ductal breast carcinomas. Cancer. 1989;64:1914-21.

16. Coates AS, Winer EP Goldhirsch A, Gelber RD, Gnant M, PiccartGebhart M, et al. Tailoring therapies improving the management of early breast cancer: St Gallen international expert consensus on the primary therapy of early breast cancer 2015. Ann Oncol. 2015;26:1533-46.

17. Miller SA, Dykes DD, Polesky HF. A simple salting out procedure for extracting DNA from human nucleated cells. Nucleic Acids Res. 1988;16:1215.

18. Zhou S, Kassauei K, Cutler DJ, Kennedy GC, Sidransky D, Maitra $A$, et al. An oligonucleotide microarray for high-throughput sequencing of the mitochondrial genome. J Mol Diagn. 2006; 8:476-82.

19. Cutler DJ, Zwick ME, Carrasquillo MM, Yohn CT, Tobin KP, Kashuk C, et al. High-throughput variation detection and genotyping using microarrays. Genome Res. 2001;11:1913-25.

20. Martinez-Outschoorn U, Sotgia F, Lisanti MP. Tumor microenvironment and metabolic synergy in breast cancers: critical importance of mitochondrial fuels and function. Semin Oncol. 2014:41:195-216. 
21. Tseng LM, Yin PH, Chi CW, Hsu CY, Wu CW, Lee LM. Mitochondrial DNA mutations and mitochondrial DNA depletion in breast cancer. Genes Chromosomes Cancer. 2006;45:629-38.

22. Cai FF, Kohler C, Zhang B, Chen WJ, Barekati Z, Garritsen HS. Mutations of mitochondrial DNA as potential biomarkers in breast cancer. Anticancer Res. 2011;31:4267-71.

23. Wallace DC. Bioenergetics in human evolution and disease: implications for the origins of biological complexity and the missing genetic variation of common diseases. Philos Trans R Soc Lond B Biol Sci. 2013;368:20120267.

24. Lisker R, Ramirez E, Briceño RP, Granados J, Babinsky V. Gene frequencies and admixture estimates in four Mexican urban centers. Hum Biol. 1990;62:791-801.

25. Bekker-Mendez C, Yamamoto-Furusho JK Vargas-Alarcón G Ize-Ludlow D, Alcocer-Varela J, Granados J. Haplotype distribution of class II MHC genes in Mexican patients with systemic lupus erythematosus. Scand J Rheumatol. 1998;27:373-6.

26. Xie HM, Perin JC, Schurr TG, Dulik MC, Zhadanov SI, Baur JA, et al. Mitochondrial genome sequence analysis: a custom bio- informatics pipeline substantially improves affymetrix Mitochip v2.0 call rate and accuracy. BMC Bioinformatics. 2011; 12:402

27. Liu VW, Shi HH, Cheung AN, Chiu PM, Leung TW, Nagley P, et al. High incidence of somatic mitochondrial DNA mutations in human ovarian carcinomas. Cancer Res. 2001;61 5998-6001.

28. Gusdon AM, Votyakova TV, Reynolds IJ, Mathews CE. Nuclear and mitochondrial interaction involving $\mathrm{mt}$-nd2 leads to increased mitochondrial reactive oxygen species production. J Biol Chem. 2007;282:5171-9.

29. Cadet J, Berger M, Douki T, Ravanat JL. Oxidative damage to DNA: formation, measurement, and biological significance. Rev Physiol Biochem Pharmacol. 1997;131:1-87.

30. Polyak K, Li Y, Zhu H, Lengauer C, Willson JK, Markowitz SD, et al. Somatic mutations of the mitochondrial genome in human colorectal tumours. Nat Genet. 1998; 20:291-3.

31. Chaney JL, Clark PL. Roles for synonymous codon usage in protein biogenesis. Annu Rev Biophys. 2015;44:143-66. 